\title{
Surgical effects of nasal transposition of inferior rectus muscle - I35 cases of acquired superior oblique palsy
}

This article was published in the following Dove Press journal:

Clinical Ophthalmology

18 April 2015

Number of times this article has been viewed

\section{Mana Okamoto \\ Akiko Kimura \\ Akiko Masuda \\ Osamu Mimura}

Department of Ophthalmology, Hyogo College of Medicine Hospital, Nishinomiya, Japan
Correspondence: Mana Okamoto Department of Ophthalmology, Hyogo College of Medicine Hospital, I-I Mukogawa-cho, Nishinomiya city, Hyogo, Japan 663-850I

Tel +81798456462

Fax $+8 I 798456464$

Email manamana429@gmail.com
Abstract: Nasal transposition of the inferior rectus (IR) muscle, which is transposed nasally with the insertion parallel to the spiral of Tillaux, could correct excyclotropia. However, as far as we are aware, there have been no reports examining the surgical effects of this procedure in multiple cases. Therefore, we examined the surgical effects of IR nasal transposition in 135 cases with acquired trochlear nerve palsy at Hyogo College of Medicine Hospital, Nishinomiya, Japan. One muscle width of IR nasal transposition corrected an average $5.6^{\circ}$ in excyclotorsion, while bilateral IR nasal transposition corrected average $10.9^{\circ}$. This result shows this procedure is accurate quantitatively. Moreover, IR nasal transposition in combination with IR recession or resection can correct vertical deviation and excyclotorsion simultaneously. The results of this study suggest that IR nasal transposition should become first-line treatment for acquired superior oblique palsy.

Keywords: spiral of Tillaux, strabismus surgery, excyclotropia, acquired trochlear nerve palsy

\section{Introduction}

The surgical treatment of acquired trochlear nerve palsy is aimed at reducing the cyclodeviation, nullifying the primary-position hypertropia and reducing any chindown head posture. ${ }^{1,2}$ Especially, in acquired superior oblique (SO) palsy, the dominant deviation problem for the patient is excyclotropia. ${ }^{3}$ However, inferior oblique weakening is usually insufficient to correct this problem. Harada and Ito described a new procedure to correct excyclotropia, which was splitting the SO and advancing the anterior half of the tendon. ${ }^{4}$ The anterior fibers are primarily responsible for the torsional action of the $\mathrm{SO}$, and the primarily vertically acting posterior fibers are left undisturbed. The Harada-Ito procedure/modified Harada-Ito procedure continues to be the surgery of choice in patients with isolated cyclodeviation, evidencing better outcome if less than $10.0^{\circ}$ of preoperative excyclotorsion and preoperative fusion exist. ${ }^{5-8}$ However, some papers have reported that the Harada-Ito procedure tends to lose its effectiveness over time and that adherence of the tendon fibers to the surface of the globe is sufficiently secure when performed with nonabsorbable sutures. ${ }^{9,10}$

Horizontal transposition of the vertical rectus muscles was reported as a new surgical technique to correct cyclodeviation. ${ }^{11}$ This report demonstrated that the nasal or temporal transposition of vertical rectus muscles aligned and parallel to the spiral of Tillaux caused cyclodeviation of the eyeball. Furthermore, vertical transposition of the horizontal rectus muscles has also been reported to correct cyclodeviation. ${ }^{12}$ These techniques utilized the fact that the superior rectus (SR) and medial rectus (MR) 
was operating by the action of incyclotorsion and the IR and lateral rectus (LR) was operating by the action of excyclotorsion. Subsequently, von Noorden et $\mathrm{al}^{13}$ reported that the surgical effect of IR nasal transposition and SR nasal transposition was approximately $7.0^{\circ}$ for the primary position and $11.0^{\circ}$ for the downward position, respectively. These effects remained stable for more than 1 year postoperatively.

Since von Noorden et al's first report, ${ }^{11}$ IR nasal transposition has been used as the first choice for treating patients with acquired and decompensated SO palsies at Hyogo College of Medicine Hospital (hereinafter, “our hospital”). Here, we report on the surgical outcomes of 135 cases of IR nasal transposition performed over 21 years from 1990, discussing both surgical effects and problems. As far as we are aware, this is the first report of IR nasal transposition on a large number of cases.

\section{Subjects and methods}

Over the 21-year period from April 1990 to March 2011, we investigated 135 patients who were diagnosed with acquired or decompensated SO palsy and underwent IR nasal transposition at our hospital, whose follow-up periods were more than 3 months after surgery. This study was approved by the Institutional Review Board of Hyogo College of Medicine Hospital.

One hundred and twenty-three cases of acquired SO palsy and 12 cases of decompensated SO palsy were included. The diagnostic criteria for acquired SO palsy and decompensated SO palsy are presented shown in Table 1. Patients with a history of strabismus surgery or visual impairment unable to undergo strabismus examination were excluded. We also excluded six cases that underwent transposition by one-third

Table I Diagnostic criteria for acquired and decompensated superior oblique palsy

\begin{tabular}{ll}
\hline SO palsy & Criteria \\
\hline Acquired & - Sudden onset \\
- & Complication of vertical deviation and \\
& excyclodeviation \\
- Exacerbation of diplopia (or vertical deviation) & in down gaze \\
- Positive BHTT & - Exclusion of myasthenia gravis and thyroid \\
& ophthalmopathy \\
- & Indeterminate onset of diplopia \\
- Complication of vertical deviation and & excyclodeviation \\
- Pecompensated & Positive BHTT \\
& ophthalmopathy
\end{tabular}

Abbreviations: SO, superior oblique; BHTT, Bielschowsky head-tilt test.

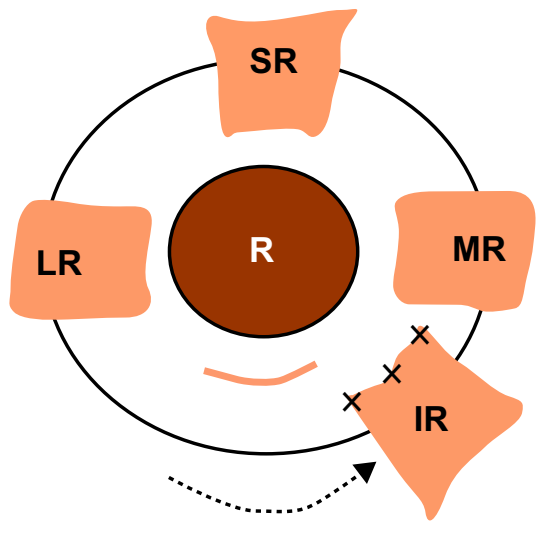

Figure I Surgical procedure of inferior rectus (IR) nasal transposition. IR was recessed and transposed nasally along with the spiral of Tillaux in the case of vertical deviation and excyclodeviation.

Abbreviations: LR, lateral rectus; MR, medial rectus; SR, superior rectus.

muscle width. The mean age of patients was 62 years old (range 19-89 years old).

Preoperatively, all patients underwent general ophthalmic examination comprising best-corrected visual acuity, anterior-segment examination, and funduscopy. In addition, vertical deviation was confirmed by the alternate prism cover test and Hess chart. Cyclodeviation was quantified by a major amblyoscope with cross-slide for primary and $15.0^{\circ}$ downward positions.

Surgery was performed under sub-Tenon's anesthesia in all patients by two surgeons (AK and OM). The surgical procedure was as follows. A limbal incision was used, exposing the IR and then suturing both sides of the muscle insertion with 6-0 absorbable sutures and severing the IR. When moving one muscle width, that temporal suture of IR was aligned to the nasal side of the IR insertion and the nasal suture of the IR was aligned to the inferior portion of the MR (Figure 1). For cases accompanied by vertical deviation, we performed IR recession or resection in addition to IR nasal transposition simultaneously.

Surgical effects were assessed by comparing preoperative and 3-month postoperative data. We investigated retrospectively the surgical effects of IR nasal transposition, participation of IR recession or resection with IR nasal transposition, and complications of IR nasal transposition.

\section{Results}

\section{Surgical effects of IR nasal transposition}

Of the 135 patients, IR nasal transposition of one muscle width, with or without IR recession or resection, were performed in 90 patients. Results are summarized in Table 2. Excyclodeviation decreased from $8.0^{\circ} \pm 0.3^{\circ}$ (mean \pm standard error) 
Table 2 Surgical effects of inferior rectus nasal transposition

\begin{tabular}{lllll}
\hline Muscle width & Cases $(\mathbf{n})$ & \multicolumn{3}{l}{ Excyclodeviation (mean \pm standard error) } \\
\cline { 3 - 5 } & & Preoperative & Postoperative & Surgical effect \\
\hline $1 / 2$ & 14 & $4.1 \pm 0.6$ & $0.9 \pm 0.3$ & $3.3 \pm 0.5$ \\
$2 / 3$ & 19 & $4.9 \pm 0.4$ & $1.6 \pm 0.4$ & $3.3 \pm 0.6$ \\
1 & 90 & $8.0 \pm 0.3$ & $2.4 \pm 0.2$ & $5.6 \pm 0.3$ \\
\hline
\end{tabular}

to $2.4^{\circ} \pm 0.2^{\circ}$ after the operation. The surgical effect of IR nasal transposition of one muscle width was $5.6^{\circ} \pm 0.3^{\circ}$. Fourteen patients underwent one-half muscle width of IR nasal transposition, with the surgical effect of $3.3^{\circ} \pm 0.5^{\circ}$, and 19 patients underwent two-third muscle width of IR nasal transposition, with the surgical effect of $3.3^{\circ} \pm 0.6^{\circ}$. For the ten patients who underwent bilateral IR nasal transposition simultaneously, the surgical effect of two muscle widths was $10.9^{\circ} \pm 0.7^{\circ}$. Therefore, IR nasal transposition of one muscle width reduced excyclodeviation to $5.5^{\circ}$ on average. For the two patients who underwent bilateral IR nasal transposition and unilateral SR muscle temporal transposition simultaneously (three muscle widths), the surgical effect was $19.0^{\circ}$ on average, making the effect per muscle $6.3^{\circ}$.

\section{Surgical effects of IR recession or resection in addition to one-muscle- width nasal transposition of IR}

In order to investigate whether IR recession or resection had a decreasing effect on excyclodeviation in IR nasal transposition, we examined the 90 patients who underwent one-muscle-width nasal transposition of IR. Results are summarized in Table 3. For eleven patients who underwent IR nasal transposition, the surgical effect was an average $5.9^{\circ}$ on excyclodeviation. For the 19 patients who underwent $1.0 \mathrm{~mm}$ of IR recession, the corrective effect of excyclodeviation was an average of $4.9^{\circ}$; for the 27 patients with 2.0 $\mathrm{mm}$ of IR recession, the average was $5.4^{\circ}$; for the 21 patients with $3.0 \mathrm{~mm}$ of IR recession, the average was $5.8^{\circ}$; for the nine patients with $4.0 \mathrm{~mm}$ of IR recession, the average was $6.2^{\circ}$; and for the three patients with $5.0 \mathrm{~mm}$ of IR recession, the average was $6.8^{\circ}$. There was no statistical significance between the amount of IR recession and the corrective effect of excyclodeviation except in three cases with $5.0 \mathrm{~mm}$ of IR recession (Pearson's correlation coefficient, $P=0.8073$ ).

By contrast, the results for the four patients who underwent IR resection in addition to IR nasal transposition were as follows: for the two patients who underwent $1.0 \mathrm{~mm}$ of IR resection, the corrective effect of excyclodeviation was an average of $6.0^{\circ}$; for the patient with $2.5 \mathrm{~mm}$ of IR resection, it was $7.0^{\circ}$; and for the patient with $4.5 \mathrm{~mm}$ of IR resection, $5.5^{\circ}$.

\section{Complications}

Recession of IR frequently associated with lower eyelid retraction. No patients in this study developed lower eyelid retraction. However, nine out of the 135 patients $(6.7 \%)$ required a second surgery due to the reappearance of diplopia in the primary position. One patient underwent a second surgery within 3 months of the first surgery, five patients were re-operated on from 6 months to 1 year following the first surgery, and three patients, 1-year postoperatively. In the patient who underwent a second surgery within 3 months, however, $5.0^{\circ}$ of cyclotorsion remained, and the subject therefore requested additional surgery. In the other patients who underwent a second surgery more than 6 months later, the surgical effect had attenuated so second surgery was performed.

\section{Discussion}

For a long time, the Harada-Ito procedure has been used as a well-established surgical technique to correct excyclodeviation. Helveston ${ }^{14}$ indicated Harada-Ito

Table 3 Relationship between amount of inferior rectus recession and corrective effect in excyclodeviation

\begin{tabular}{|c|c|c|c|c|}
\hline \multirow[t]{2}{*}{ Recession (mm) } & \multirow[t]{2}{*}{ Cases (n) } & \multicolumn{3}{|c|}{ Excyclodeviation (mean \pm standard error) } \\
\hline & & Preoperative & Postoperative & Surgical effect \\
\hline 0 & II & $9.8 \pm 0.9$ & $3.9 \pm 0.9$ & $5.9 \pm 0.9$ \\
\hline I & 19 & $7.8 \pm 0.6$ & $2.9 \pm 0.5$ & $4.9 \pm 0.7$ \\
\hline 2 & 27 & $7.4 \pm 0.6$ & $2.0 \pm 0.3$ & $5.4 \pm 0.5$ \\
\hline 3 & 21 & $7.6 \pm 0.5$ & $1.8 \pm 0.4$ & $5.8 \pm 0.6$ \\
\hline 4 & 9 & $8.6 \pm 0.8$ & $2.4 \pm 0.8$ & $6.2 \pm 0.8$ \\
\hline 5 & 3 & $9.5 \pm 0.8$ & $2.7 \pm 0.9$ & $6.8 \pm 0.4$ \\
\hline
\end{tabular}


procedure to be ideal for an isolated, acquired, symptomatic excyclotropia as the only presenting sign of a very mild SO paresis without a vertical strabismus component. Correction of the vertical deviation in patients with SO palsy by strengthening the action of the SO and weakening the action of the inferior oblique suffices, as a rule, to correct the accompanying excyclotropia as well. ${ }^{15}$

Incidentally, such patients respond equally well to nasal transposition of the IR muscle of the affected eye, rather than to the Harada-Ito procedure. However, in 1990, a new surgical procedure was presented by von Noorden and Chu. ${ }^{11}$ Horizontal transposition of vertical muscles, especially IR nasal transposition, stably decreased the excyclo effect of the IR. The advantages of this surgical procedure with/ without recession of IR include its being easier to perform than surgery of SO and enabling the simultaneous correction of vertical deviation and cyclodeviation. However, as von Noorden et $\mathrm{al}^{13}$ reported 17 cases; Ohmi et $\mathrm{al}^{16}$ three cases; and Nemoto et al ${ }^{17} 17$ cases, as far as we are aware, no reports have studied the effects of this surgical procedure on a large number of cases. Here, we investigated the surgical effect of IR nasal transposition in 135 patients with acquired and decompensated SO palsies. While the mean corrective effect in excyclodeviation for IR nasal transposition of one muscle width was $5.6^{\circ}$ in our hospital, the corrective effect of excyclodeviation per muscle for bilateral IR nasal transposition of one muscle width (two muscles) was $5.5^{\circ}$, thereby indicating quantitative stability. Since von Noorden et $\mathrm{l}^{13}$ reported $7.0^{\circ}$, Ohmi et al ${ }^{16}$ reported $7.8^{\circ}$, and Nemoto et $\mathrm{al}^{17}$ reported $6.2^{\circ}$, the corrective effects of cyclodeviation range from approximately $5.5^{\circ}$ to $7.0^{\circ}$. Moreover, regarding corrective effects in cyclotorsion of Harada-Ito procedure, Bradfield et $\mathrm{al}^{6}$ reported $12.0^{\circ}\left(6.0^{\circ}\right.$ per eye $)$ of correction in 12 patients who underwent bilateral SO tendon advancement and $8.0^{\circ}$ in seven patients who underwent unilateral surgery, while Nishimura and Rosenbaum ${ }^{9}$ reported $9.7^{\circ}$ of corrective effect in 17 patients. Therefore, the surgical effect of HaradaIto procedure appeared to be stronger than that of IR nasal transposition. However, weakening of the corrective effect of Harada-Ito procedure over the long-term has been considered as a problem, because these procedures are strengthening palsied muscle. As a practical matter, Nishimura and Rosenbaum ${ }^{9}$ also reported that while the corrective effect of cyclotorsion was $9.7^{\circ}$ at 2 months postoperatively, this was reduced to $5.4^{\circ}$ at 18 months postoperatively.

We investigated whether IR recession or resection in combination with IR nasal transposition affected corrective effect in cyclotorsion. Surgical outcomes were not affected by the amount of IR recession or resection. However, as we investigated IR recession up to $5.0 \mathrm{~mm}$ and resection up to $2.5 \mathrm{~mm}$ in this study, there is a possibility that large amounts of recession or resection may affect the surgical effect of IR nasal transposition for excyclotorsion.

In regard to complications, while there had been concern over lower eyelid retraction caused by IR recession, no cases exhibited significant lower eyelid retraction. This may have been because IR recession was only conducted up to $5.0 \mathrm{~mm}$. Recession greater than $5.0 \mathrm{~mm}$ may cause lower eyelid retraction, therefore, in cases with severe vertical deviation and excyclodeviation; it is best to treat cases with SR recession of the contralateral eye when $5.0 \mathrm{~mm}$ of IR recession and nasal transposition is insufficient to correct vertical deviation. No cases exhibited disturbance in ocular motility such as iatrogenic Brown's syndrome, which is frequently found with the Harada-Ito procedure. ${ }^{18,19}$ Furthermore, IR nasal transposition can conserve the superior conjunctiva which is important for glaucoma surgery.

\section{Conclusion}

IR nasal transposition is a simple and safe procedure for treatment of excyclodeviation compared to the Harada-Ito procedure. This procedure can treat vertical deviation and excyclodeviation simultaneously with IR recession or resection in addition to IR nasal transposition.

Therefore, we think it is likely that IR nasal transposition will be become the first choice for treating patients with vertical and excyclodeviation, which is typically caused by acquired SO palsy.

\section{Disclosure}

The authors report no conflicts of interest in this work.

\section{References}

1. Helveston EM, Mora JS, Lipsky SN, et al. Surgical treatment of superior oblique palsy. Trans Am Ophthalmol Soc. 1996;94:315-328.

2. Bagheri A, Fallahi MR, Abrishami M, Salour H, Aletaha M. Clinical features and outcomes of treatment for fourth nerve palsy. JOphthalmic Vis Res. 2010;5(1):27-31.

3. Mitchell PR, Parks MM. Surgery of bilateral superior oblique palsy. Ophthalmology. 1982;89(5):484-488.

4. Harada M, Ito Y. Visual correction of cyclotropia. Jpn J Ophthalmol. 1964;8:88-96.

5. Ying HS, Darbandi B, Shan X, Barker P, Miller NR, Zee DS. Quantitative eye movement recordings in a patient with acquired bilateral superior oblique palsy before and after a bilateral Harada-Ito procedure. Strabismus. 2007;15(3):137-147.

6. Bradfield YS, Struck MC, Kushner BJ, Neely DE, Plager DA, Gangnon RE. Outcomes of Harada-Ito surgery for acquired torsional diplopia. J AAPOS. 2012;16(5):453-457.

7. Lemos J, Eggenberger E. Clinical utility and assessment of cyclodeviation. Curr Opin Ophthalmol. 2013;24(6):558-565. 
8. Li Y, Zhao K. Superior oblique tucking for treatment of superior oblique palsy. J Pediatr Ophthalmol Strabismus. 2014;51(4):249-254.

9. Nishimura JK, Rosenbaum AL. The long-term torsion effect of the adjustable Harada-Ito procedure. J AAPOS. 2002;6(3):141-144.

10. Griffiths HJ, Burke JP. Temporary incyclotorsion following surgical correction of bilateral superior oblique palsy. J AAPOS. 2007;11(1): $65-67$.

11. von Noorden GK, Chu MW. Surgical treatment options in cyclotropia. J Pediatr Ophthalmol Strabismus. 1990;27(6):291-293.

12. Buckley EG, Townshend LM. A simple transposition procedure for complicated strabismus. Am J Ophthalmol. 1991;111(3):302-306.

13. von Noorden GK, Jenkins RH, Chu MW. Horizontal transposition of the vertical rectus muscles for cyclotropia. Am J Ophthalmol. 1996; 122(3):325-330.

14. Helveston EM. Telemedicine: distance medicine. In: Surgical Management of Strabismus. 5th ed. Belgium: Wayenborgh Publishing; 2005:327-328.
15. Plager DA. Oblique muscle dysfunction. In: Plager DA, editor. Strabismus Surgery: Basic and Advanced Strategies. Oxford and New York, NY: Oxford University Press; 2004:35-58.

16. Ohmi G, Fujikado T, Ohji M, Saito Y, Tano Y. Horizontal transposition of vertical rectus muscles for treatment of excyclotropia. Graefes Arch Clin Exp Ophthalmol. 1997;235(1):1-4.

17. Nemoto Y, Kaneko H, Sakaue T, Kobota N, Maruo T, Oshika K. Skew transposition of vertical rectus muscles for excyclovertical deviation. Jpn J Ophthalmol. 2000;44(4):428-432.

18. Simons BD, Saunders TG, Siatkowski RM, et al. Outcome of surgical management of superior oblique palsy: a study of 123 cases. Binocul Vis Strabismus Q. 1998;13(4):273-282.

19. Gräf M, Lorenz B, Eckstein A, Esser J. Superior oblique tucking with versus without additional inferior oblique recession for acquired trochlear nerve palsy. Graefes Arch Clin Exp Ophthalmol. 2010;248(2): $223-229$.
Clinical Ophthalmology

\section{Publish your work in this journal}

Clinical Ophthalmology is an international, peer-reviewed journa covering all subspecialties within ophthalmology. Key topics include: Optometry; Visual science; Pharmacology and drug therapy in eye diseases; Basic Sciences; Primary and Secondary eye care; Patien Safety and Quality of Care Improvements. This journal is indexed on

Submit your manuscript here: http://www.dovepress.com/clinical-ophthalmology-journal

\section{Dovepress}

PubMed Central and CAS, and is the official journal of The Society of Clinical Ophthalmology (SCO). The manuscript management system is completely online and includes a very quick and fair peer-review system, which is all easy to use. Visit http://www.dovepress.com/ testimonials.php to read real quotes from published authors. 